\title{
Identification of artificial orpiment in the interior decorations of the Japanese tower in Laeken, Brussels, Belgium
}

\author{
Marc Vermeulen ${ }^{1 *}$, Jana Sanyova ${ }^{1}$ and Koen Janssens ${ }^{2}$
}

\begin{abstract}
In this paper, we used a multi-technique approach in order to identify the arsenic sulfide pigment used in the decorative panels of the Japanese tower in Laeken, Belgium. Our attention was drawn to this particular pigment because of its relatively good conservation state, despite its known tendency to fade over time when exposed to light. The pigment was used with different painting techniques, bound with oil and urushi in the lacquers and with an aqueous binder in the mat relief panels. In the latter case it is always applied as an underlayer mixed with ultramarine blue. This quite unusual pigment mixture also shows a good state of preservation.

In this study, the orpiment used for the Japanese tower has been identified as an amorphous arsenic sulfide glass $\left(A s_{x} S_{x}\right)$ with the aid of light microscopy, PLM, SEM-EDX and Raman microscopy. The pigment features different degrees of $\mathrm{As}_{4} \mathrm{~S}_{4}$ monomer units in its structure, also known as realgar-like nano-phases. This most likely indicates different synthesis processes as the formation of these $\mathrm{As}_{4} \mathrm{~S}_{4}$ monomers is dependent of the quenching temperature $(\mathrm{Tq})$ to which the artificial pigment is exposed during the preparation phase.
\end{abstract}

Keywords: Orpiment, Arsenic sulfide glass, Raman spectroscopy, Polarized light microscopy

\section{Introduction and historical context}

In characterization studies of arsenic sulfide pigments, there is a high probability that conclusions regarding the exact nature of the compounds present are drawn prematurely. In many cases, the encountered arsenic sulfide is recognized as being a mineral orpiment while in reality it appears to be pararealgar - the yellow degradation phase of realgar - while in others, distinction between natural and artificial orpiment is not made. Contradictions about the exact nature of arsenic sulfide pigments can also be found in published scientific literature or pigment encyclopedias, sometimes confusing realgar with an arsenic sulfide glass of unknown composition [1]. So-called artificial orpiment can be produced using two different processes, wet and dry, using different starting materials [2,3]. In any case, arsenic sulfide pigments are the result but the structure and properties of the reaction products can be different. To understand its composition and characteristics,

\footnotetext{
* Correspondence: marc.vermeulen@kikirpa.be

'Laboratory of polychrome artifacts, Royal Institute for Cultural Heritage, Parc du Cinquantenaire 1, B-1000 Brussels, Belgium

Full list of author information is available at the end of the article
}

a multi-technique approach is required. Each used technique, from SEM-EDX to Raman spectroscopy and polarized light microscopy, can increase the knowledge about the processes behind artificial arsenic sulfide. Although the use of such a pigment in a 20th-century artifact seems rather uncommon, its good conservation state is even more striking when one considers how instable this material is over time.

By the end of the 19th century, Europe was fascinated by Asia, notably by China and Japan. The latter country was only opened to Western commerce and travellers in 1853 [4-6]. This fascination had influenced the arts as illustrated by the many Japanese influences in impressionist paintings [6,7], in literature [4] or in architecture with the example of La Pagode, a Parisian movie theater/dance hall built in 1896 [8]. All of these Japanese-inspired creations date from the period 1850-1910. This movement, also called Japonism, was most likely stimulated by the world expositions organized in Europe by the end of the 19th century. While the 1867 and 1878 fairs witnessed the first exhibition of Japanese artifacts and rapidly promoted this form of art in Europe [4,5], the Japan-like representation 
reached its climax during the world fair in 1900 in Paris with the Panorama du tour du Monde and its three imposing towers [9]: one Moorish in style, another one Hindu and the third one, the most massive, Japanese (Figure 1). King Leopold II of Belgium visited this Panorama du tour du monde in 1900 and hired the architect Alexandre Marcel to build a pagoda similar to the Japanese one for the fair on the Royal domain in Laeken, Brussels, Belgium [10].

The construction of this Japanese tower took three years and it was inaugurated in 1905 . The main entrance porch was taken from the original Parisian pagoda while other elements such as the sliding doors and decorated panels were shipped from Japan; in some cases, these artifacts were re-used elements from disassembled temples. Finally, some elements were created in Europe, by European craftsmen [10,11].

Its fate has not been as bright as the King had intended: due to construction defects, the first floor allegedly served as his unofficial office for only one year and was then abandoned, together with the four other floors [11]. Afterwards, the lobby, the main staircase and the ground floor were transformed into the Far East Museum managed by the Royal Museums of Art and History, Brussels, Belgium. Due to their limited access, the first to fifth floors did not suffer as much from the visiting public as the ground floor, but the materials present here did degrade drastically due to unsuitable conservation conditions resulting from the aforementioned construction defects. An interdisciplinary study of the tower for a later conservation/ restoration has been undertaken to identify the materials used in the decorative elements ${ }^{\mathrm{a}}$. During this investigation, many sulfur-containing pigments such as mercury

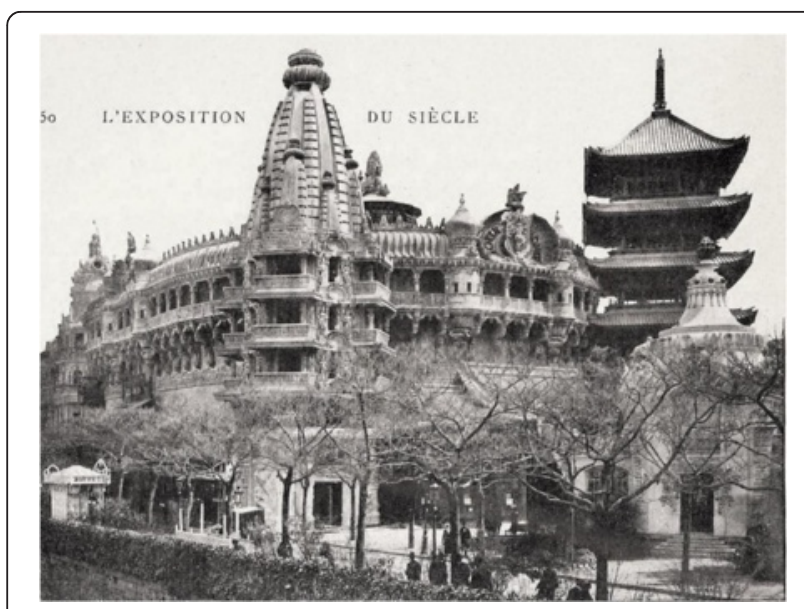

Figure 1 Photograph of the Panorama du tour du monde with, on the South-East side (left hand side of the photograph) the Hindu style tower and on the North-East side the Japanese pagoda that was used as model for the Japanese tower in Laeken, Belgium. sulfide, ultramarine blue or arsenic sulfide have been identified. These pigments present different levels of degradation based on their type and localization within the tower. For example, the mercury sulfide pigment was generally found to be much degraded on the fourth floor of the tower (Figure 2a) whereas arsenic sulfide found one level below, with more or less the same light exposure, did not exhibit any apparent degradation (Figure 2b). This apparent stability of arsenic sulfide, a pigment notorious for its instability, seemed rather uncommon. The light-induced degradation process of arsenic sulfide transforms it from bright yellow arsenic sulfide $\left(\mathrm{As}_{2} \mathrm{~S}_{3}\right)$ to white/transparent arsenic trioxide $\left(\mathrm{As}_{2} \mathrm{O}_{3}\right)$ [12-14]. This phenomenon of fading seems to be a surface alteration, the lower part of the paint system being unaffected [15]. Similarly, red vermillion $(\mathrm{HgS})$ is converted to grey/black calomel $\left(\mathrm{Hg}_{2} \mathrm{Cl}_{2}\right)$ by exposure of light as can be observed on the red decorative panels of the fourth floor of the tower [16]. Previous studies [2,3] have focused on the synthesis and analysis of arsenic sulfide pigments and five major types of arsenic sulfides have been identified based on their origin or manufacturing processes: natural orpiment obtained from mining, so-called artificial orpiment obtained from a wet process (never encountered in any works of art up to now) and from several dry processes (three types depending on the original reactants) [17]. Except for the dry process pigment obtained from natural orpiment and sulfur as starting materials which can be considered as artificial orpiment, all of the other forms have to be referred as arsenic sulfide glass [18].

To understand this unusual arsenic sulfide stability, the characterization of the pigment used in the panels has been undertaken using a multi-technique approach. Since arsenic sulfide is a good Raman scattering material, Raman spectroscopy (MRS) along with polarized light microscopy (PLM) seemed the best suited methods to identify the type of arsenic sulfide present in the tower. Nonetheless, scanning electron microscopy coupled with $\mathrm{X}$-Ray detection (SEM-EDX) also seemed useful to some extent. On the other hand, more sophisticated methods such as microscopic X-Ray diffraction ( $\mu$-XRD) or time of flight secondary ion mass spectrometry (ToF-SIMS) did not seem very promising due to the poor ionization of the arsenic in the case of SIMS and the lack of signal - except for the broad band characteristic for amorphous material in the case of $\mu$-XRD.

\section{Materials and methods}

\section{- Samples}

Among 165 samples taken from the tower for a complete technical study, a total of 24 samples containing arsenic sulfide pigment and sampled on different floors were selected. The samples were 


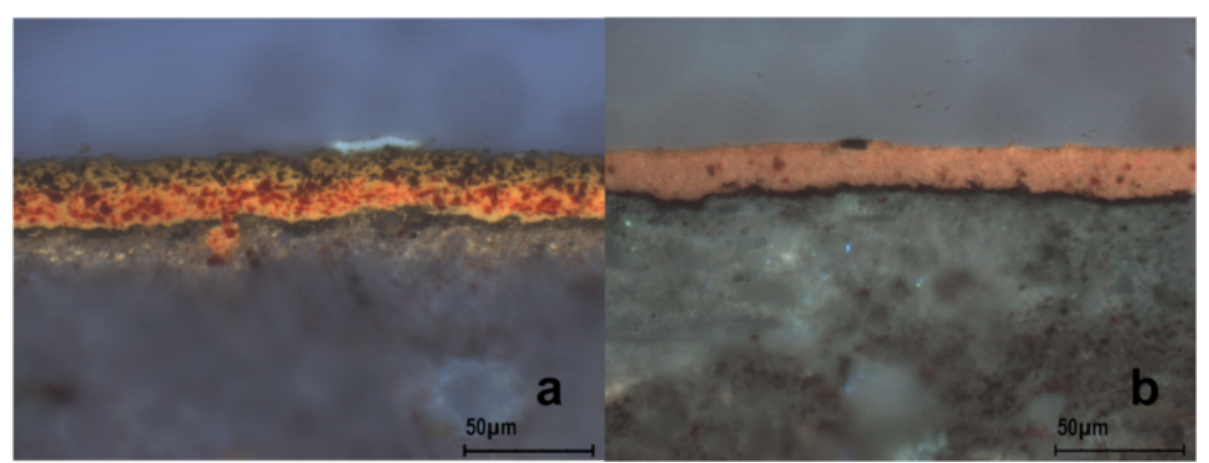

Figure 2 Cross-sectional photomicrographs of samples (a) C90.065 and (b) C90.101 under ultraviolet illumination. C90.065 clearly shows color-modified pigment particles in the upper part of the vermilion layer (darkening) while C90.101 does not exhibit any sign of color-changed pigments.

numbered P201.061 to P210.036 for archiving. They were then mounted as cross-sections (C87.129 to C90.158) in order to be analyzed. The cross-sections were prepared by embedding the samples between acrylic resin cubes. The bulk sample was first fixed to a $1 \mathrm{~cm}^{3}$ poly (methyl methacrylate) cube using a white PVA glue, after which the acrylic copolymer resin (Spofacryl ${ }^{\circ}$, Spofa Dental CZ-10031, Prague) was poured on the sample and the second cube placed on top. The cross-sections thus obtained were left to dry, then polished with water until the sample surface was nearly exposed. Then, polishing was continued in set circumstances using Micro Mesh $\odot$ polishing cloths in a sequence of grits (2400, 4000, 6000 and 8000 mesh) leading to a mirror-like surface. In the case of the reference samples, a JEOL Cross Section Polisher IB-09010CP (JEOL, Tokyo, Japan) was used for 12 hours with a $4.0 \mathrm{kV}$ accelerating voltage, 4.4 argon gas flow and a swinging stage. The cross-sections were photographed with an optical microscope Axio Imager 2 (Carl Zeiss, Oberkochen, Germany) under visible and ultraviolet light (excitation bandpass filter from 390 to $420 \mathrm{~nm}$ ) with magnifications up to 500x. Reference samples used in this study were the natural orpiment (Kremer Pigmente GmbH \& Co, Aichstetten, Germany) and laboratory-prepared arsenic sulfide glass. The latter was synthesized by mixing arsenic trioxide with sulfur $(1: 1)$ in a glass tube and heating it for a few minutes over a Bunsen burner as described by Rötter [2]. After grinding, a fraction of the material was mixed with Arabic gum (2/3 in water) until a good consistency was reached. It was then applied on a calcium carbonate coated board before being mounted as a cross-section; other material was kept loose for PLM analysis.

- Methods and instrumentation

\section{SEM-EDX}

SEM analyses (backscattered electron images, elemental mapping and point analyses) were carried out on goldcoated (SPI-MODULE ${ }^{\text {tx }}$ Sputter Coater, SPI, West Chester, PA, USA) cross-sections using a JEOL JSM6300 scanning electron microscope (JEOL, Tokyo, Japan) equipped with Pentafet $\mathrm{Si}(\mathrm{Li})$ and BSE (Tetra Link) X-ray detectors, both from Oxford Instruments. EDX-analyses were run at an acceleration voltage of $15 \mathrm{kV}$ and a working distance of $15 \mathrm{~mm}$. Data was collected using the INCA software system, v. 4.06 (Oxford Instruments).

\section{Micro-Raman spectrometry (MRS)}

Micro-Raman spectra were acquired with a Renishaw inVia multiple laser dispersive Raman spectrometer with a Peltier-cooled (203 K), near-infrared enhanced, deepdepletion CCD detector $(576 \times 384$ pixels $)$ using a highpower diode laser (Toptica Photonics XTRA, Graefelfing (Munich), Germany) operating at $785 \mathrm{~nm}$ in combination with a $1200 \mathrm{l} / \mathrm{mm}$ grating. Based on the particle size, samples were analyzed using either the $50 x$ or $100 x$ objectives in a direct-coupled Leica DMLM microscope with enclosure. To avoid degradation or heat induced physical changes, the power on the samples was reduced to $1 \mathrm{~mW}$ with neutral density filters. Integration times of 30 seconds and 5 accumulations were employed; this resulted in an adequate signal-to-noise ratio. Spectra were acquired using the Wire 2 Raman software and were subsequently baseline corrected when necessary.

\section{PLM}

PLM was carried out on a Zeiss Axio Imager 2 microscope (Carl Zeiss, Oberkochen, Germany) using a 50x or 100x objective. Samples were dispersed and mounted in Canada balsam $(\mathrm{n}=1.55)$ and observed in slightly polarized or cross-polarized light. 


\section{Results and discussion}

Due to the complexity of the sampling and despite the many samples that were taken/studied, only three samples will be discussed here. They are representative of the arsenic sulfide found and the different techniques in which it was used: samples C90.058 and P210.011 (loose material) are representative for arsenic sulfide mixed with ultramarine blue, bound with protein-based medium and used as underlayer; sample C90.094 (P209.066) corresponds to arsenic sulfide mixed with Prussian blue, used in finishing layers in an urushi-containing oil medium ${ }^{\text {b }}$; finally, sample C90.101 (P209.074) features unmixed arsenic sulfide used in urushi-containing finishing layers.

For each sample, the same analytical procedure was followed: after embedding into cross-sections, the arsenic and sulfur distribution was recorded via SEM-EDX, the yellow particles were analyzed by means of Raman spectroscopy. Then, a fraction of the remaining loose sample was dispersed in Canada balsam for PLM analysis. The same procedure was used for the natural orpiment and laboratory-made arsenic sulfide used as reference samples.

\section{SEM-EDX}

SEM backscattered electron images of the samples exhibit irregularly shaped and sized particles (Figure 3a, b and $c$ ). The high- $Z$ particles have both round and sharp edges. Semi-quantitative SEM-EDX analyses have been undertaken on these high- $\mathrm{Z}$ particles and in all cases present a similar composition: sulfur (47 weight $\% \pm 6 \%$ ) and arsenic (53 weight $\% \pm 6 \%$ ). This composition allowed us to identify these particles as an arsenic sulfide pigment. According to the backscattered electron images (Figure 3), the size of those particles is rather variable and ranges from 2 to $10 \mu \mathrm{m}$.

The nature of the arsenic sulfide pigment - natural orpiment, artificial orpiment or arsenic sulfide glass - cannot be determined with SEM-EDX analyses only. Nevertheless, none of the foliated structure or mica-like appearance characteristic for natural orpiment (Figure 4a) often described in the literature $[2,13,19,20]$ is observed in the Japanese tower samples; rather, they feature a strong resemblance to the structural pattern of the arsenic sulfide glass (Figure 4c) also very similar to the pigment with conchoidal fractures reported in Grundmann et al. [3] and confusingly reported as natural orpiment in Eastaugh et al. [1]. This strongly suggests the use of synthetic arsenic sulfide rather than the natural form of the pigment.

FitzHugh described the amorphous synthetic arsenic sulfide particles prepared through wet chemistry from thioacetamide solution round in morphology with a particle size of about $1 \mu \mathrm{m}$ [13]. Grundmann and Rötter differentiated the extremely homogeneous, fine $(1-2 \mu \mathrm{m}$ in diameter) bright yellow particles when obtained from a thioacetamide solution described by FitzHugh from the even smaller $(0.1-0.4 \mu \mathrm{m})$ particles obtained when prepared from hydrogen sulfide [3]. On the other hand, synthetic arsenic sulfide pigment produced by the dry process is described as being likely to be composed of fine to medium particles [19] with an average size of $4 \mu \mathrm{m}$ depending on the grinding [21]. The dry processes give rise to glassy arsenic sulfide cakes (Figure $4 \mathrm{~b}$ ) that contain irregularly shaped and sized particles with conchoidal fractures after grinding as described in the literature $[3,19]$ and as observed in the cross-sections of the laboratory-made $g-\mathrm{As}_{\mathrm{x}} \mathrm{S}_{\mathrm{x}}$ (Figure 4c). Because the pigment investigated in the frame of this study is an artificial arsenic sulfide pigment, the size, and shape of the particles observed in Figure 3 tend to indicate a pigment obtained from a dry rather than from a wet process.

\section{MRS}

Raman spectra show the same features in all of the three samples discussed here: a major broad band at $337 \mathrm{~cm}^{-1}$ with a shoulder at $362 \mathrm{~cm}^{-1}$ (Figure 5) as well as small bands at $234 \mathrm{~cm}^{-1}$ and $471 \mathrm{~cm}^{-1}$. The band at $471 \mathrm{~cm}^{-1}$ is always encountered but can range from small to

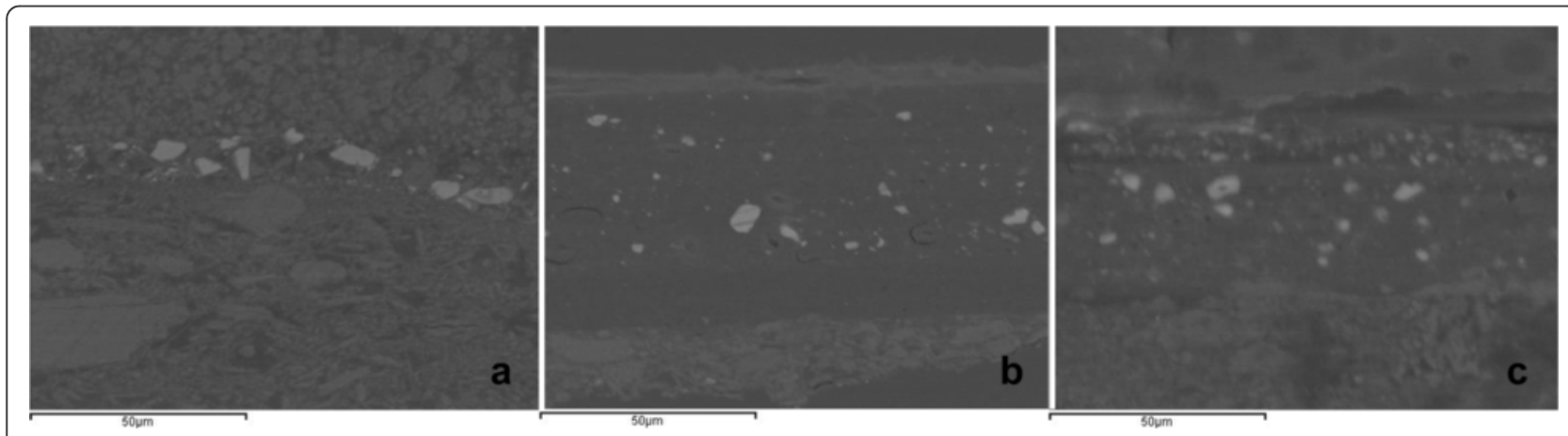

Figure 3 Backscattered electron images of samples (a) C90.058, (b) C90.094 and (c) C90.101. In all cross-sections, the high-Z particles have been identified as arsenic sulfide. 


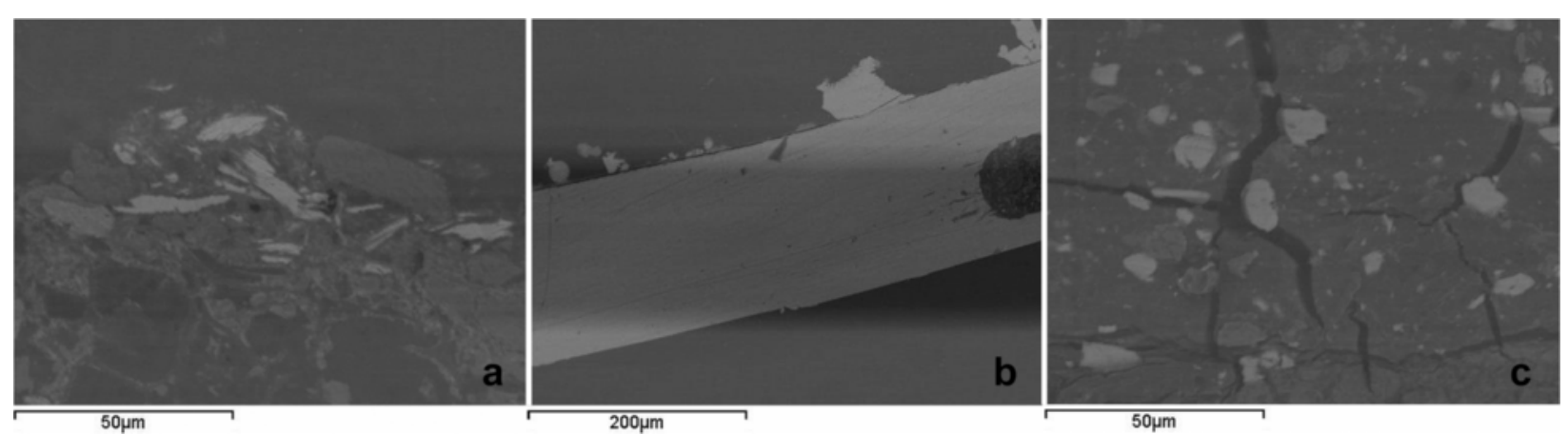

Figure 4 Backscattered electron images for (a) natural orpiment reference material, (b) laboratory-made arsenic sulfide glass cake (b) before and (c) after grinding.

medium in intensity. It most likely corresponds to sulfur remainders from the dry process preparation. Indeed, when analyzed in Raman spectroscopy, sulfur has major bands at 219 and $473 \mathrm{~cm}^{-1}$ (Figure $6 \mathrm{c}$ ). In that regard, the band at $218 \mathrm{~cm}^{-1}$ observed for sample C90.101 (Figure 5c) can also be considered as a feature for some sulfur remainder. Even though the yellow pigment in the three cross-sections has been identified as arsenic sulfide by the presence of arsenic and sulfur in SEM-EDX, these wavenumbers do not correspond to the one observed for natural orpiment $(136,154,179,202,293,311,354$, 367 (sh), $383 \mathrm{~cm}^{-1}$ ) and the observed spectra do not match any of the references (Figure 6a). Comparison of the spectra obtained with laboratory-synthetized arsenic sulfide analyzed with Raman spectroscopy (Figure 6b) shows that the pigment used is an arsenic sulfide glass. The different ratios of $\mathrm{As}_{4} \mathrm{~S}_{4}$ monomer units in its structure (band at $234 \mathrm{~cm}^{-1}$ as well as the shoulder to the main band at $360 \mathrm{~cm}^{-1}$ ) [22,23] between C90.101 (Figure 5c) and the two other cross-sections (Figure 5ab), most likely indicates that the orpiment used has been synthetized following different conditions. Indeed, the Raman bands for the $\mathrm{As}_{4} \mathrm{~S}_{4}$ monomer units can give an indication on the quenching temperature (Tq); the more important the intensities, the more important the quenching temperature [22]. Here, the small bands observed for C90.058 (a) and C90.094 (b) most likely indicate a midrange quenching temperature whereas the more intense bands observed for sample C90.101 (c) would indicate a much higher Tq. Based on the comparison of our spectra with the ones obtained by Georgiev et al. [22], the quenching temperature for $\mathrm{C} 90.058$ and $\mathrm{C} 90.094$ could be around $450^{\circ} \mathrm{C}$ and $550^{\circ} \mathrm{C}$ for $\mathrm{C} 90.101$. According to Bonazzi et al. [24] and Grundmann et al. [18], the $\mathrm{As}_{4} \mathrm{~S}_{4}$

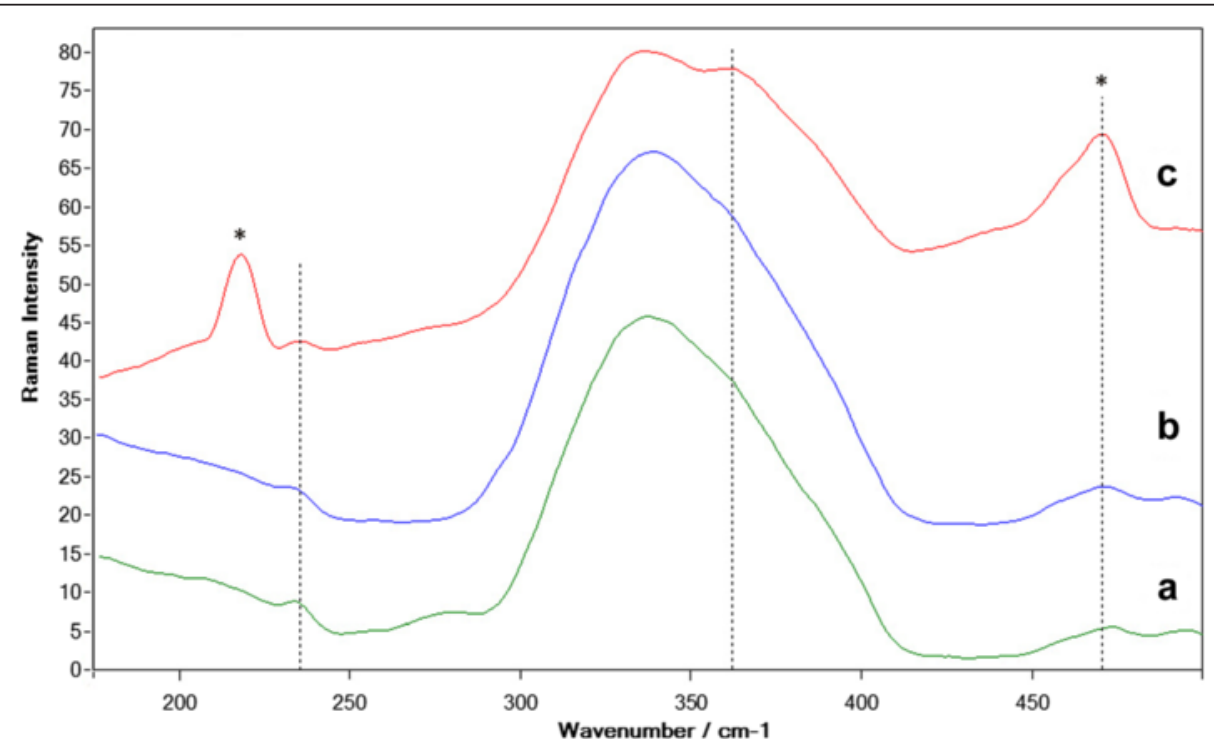

Figure 5 MRS spectra for the arsenic sulfide pigment in samples (a) C90.058, (b) C90.094 and (c) C90.101, exhibiting characteristic bands for $\mathbf{g}-\mathrm{As}_{\mathbf{x}} \mathrm{S}_{\mathbf{x}}$ (cfr. Figure $\mathbf{5 b}$ ). The stars * indicate peaks characteristic for sulfur. 


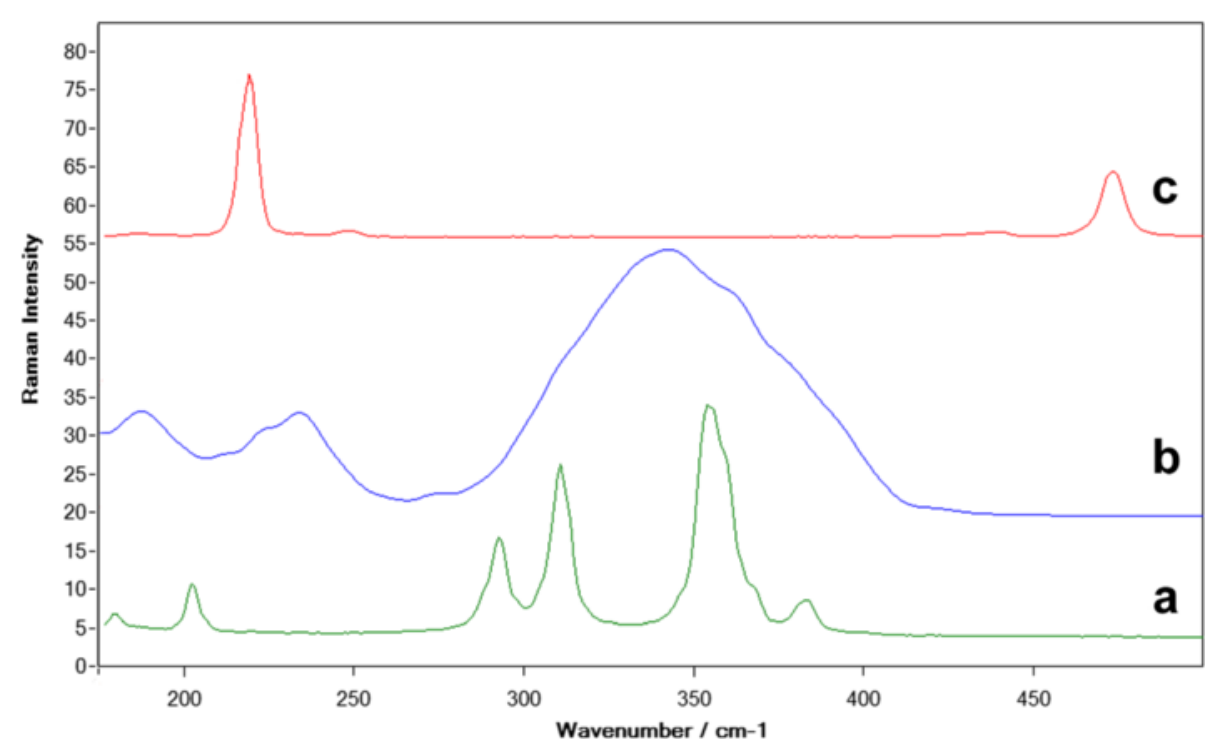

Figure 6 MRS reference spectra for (a) natural orpiment, (b) laboratory-synthetized arsenic sulfide glass ( $g$ - $\left.A s_{x} S_{x}\right)$ and (c) sulfur.

monomer units present in the arsenic sulfide glass most likely correspond to a mid-state between the $\mathrm{As}_{4} \mathrm{~S}_{4} \beta-$ phase and the $\mathrm{As}_{4} \mathrm{~S}_{4} \mathrm{X}$ - phase because of broader bands observed at 219, 235 and $245 \mathrm{~cm}^{-1}$ than expected for the more molecular ordered realgar or $\beta$ - phase. Even though Raman spectroscopy was very helpful for identifying the type of arsenic sulfide used in the decorative panels of the Japanese tower as arsenic sulfide glass, this technique does not provide any information on the starting materials.

\section{PLM}

Polarized Light Microscopy can provide information about the starting materials. Thorough investigation of the shapes and interference colors as well as comparison with reference materials are very helpful in this regard $[2,17,19]$. Indeed, natural orpiment crystals have a pronounced layer lattice with angular and lamellar-foliated morphology [1].
They show anisotropy effects and green to blue interference colors when observed under slightly polarized to cross polar light (Figure 7a) [19]. On the other hand, due to its isotropic characteristic Arsenic sulfide glass does not show these interference colors and varies from bright yellow to dark when working under crossed polarizers (Figure 7b). The internal light reflection within this material leads to an image showing a spherical yellow particle with a dark cross in the middle (top right corner of Figure 7b) [2].

Thorough investigation under microscope of the three selected samples did not reveal particles with interference colors; rather, spherical particles with distinctive features of arsenic sulfide glass comparable to the one found in literature - dark center, round edges, bright yellow/dark brown/yellow areas, conchoidal fractures [3,19] - were observed (Figure 8). This most likely indicates that no natural orpiment was used as a starting material for the
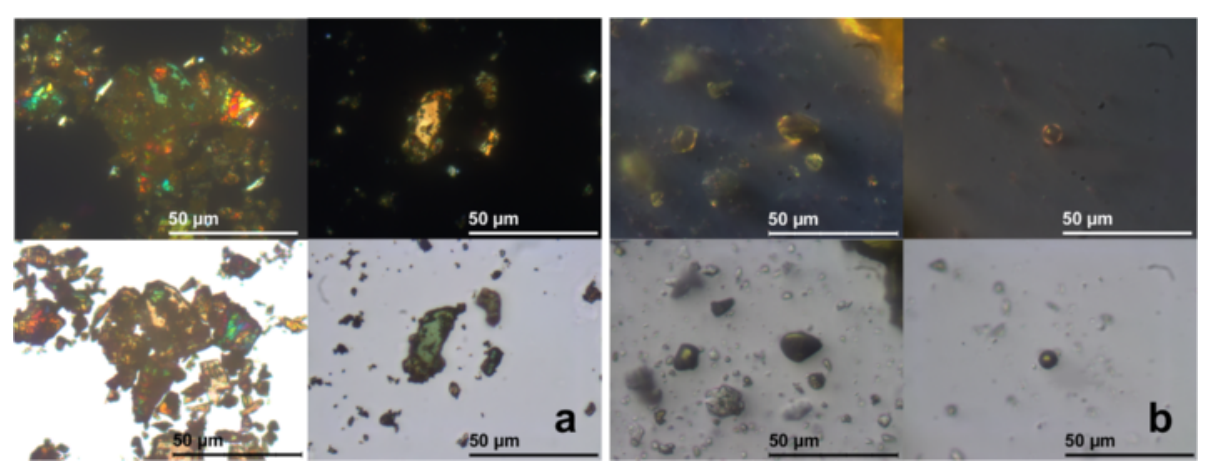

Figure 7 Polarized light photomicrographs of (a) natural orpiment and (b) laboratory-synthetized arsenic sulfide glass ( $\mathrm{g}$-As $\mathrm{S}_{\mathrm{x}}$ ) under non-polarized and crossed-polarizer illumination. 


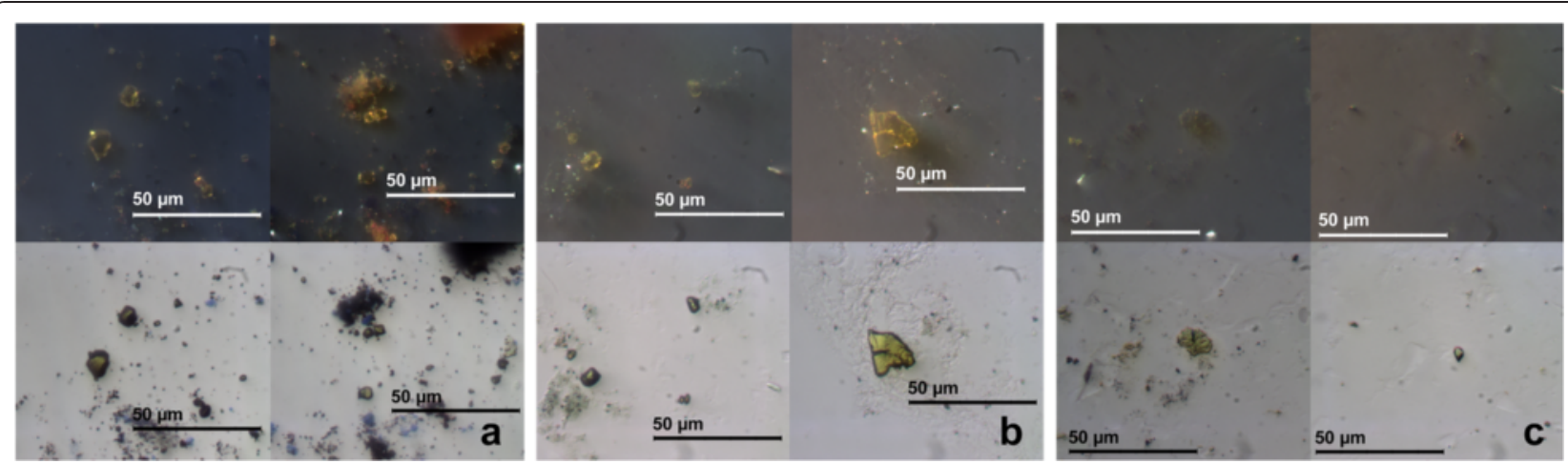

Figure 8 Polarized light microphotographs of (a) P210.011, (b) P209.066 and (c) P209.074 under non-polarized and cross-polar illumination.

synthesis of the pigment, since otherwise grains of this material would have been found in the thin section [21]. Compressed corners and edges resulting from crushing round particles can give information on the brittle deformation structures. These structures can be observed in Figure $8 \mathrm{~b}$ and $\mathrm{c}$. In this case, the deformations are either due to the pigment preparation before use or to the sample preparation for PLM analysis. PLM photomicrographs of the selected samples strongly suggest the use of arsenic sulfide glass synthetized from arsenic oxide and sulfur as described by Grundmann and Rötter [3].

\section{Conclusion}

Scanning Electron microscopy coupled with an EDX detector, Micro- Raman spectroscopy and polarized light microscopy have been used as part of a multi technique approach to identify the arsenic sulfide pigment(s) used in the decorative panels of the Japanese tower in Laeken, Belgium. Table 1 is a summary of the results obtained from the representative samples discussed here and from the reference materials. Based on the size and shape of the particles (SEM-EDX data), the wavenumber and spectrum profile obtained in Raman spectroscopy as well as the optical properties of the pigments in PLM, the arsenic sulfide that was employed, could be identified as arsenic sulfide glass $\left(\mathrm{g}-\mathrm{As}_{\mathrm{x}} \mathrm{S}_{\mathrm{x}}\right)$. This material was synthesized from arsenic trioxide and sulfur as suggested by the sulfur remainders detected in Raman spectroscopy. No remainders of natural orpiment were found during the thorough microscopic investigation of the three samples.

Table 1 Recapitulative table for the two reference materials and the 3 representative types of arsenic sulfide/ techniques found in the decorative panels of the Japanese tower in Laeken, Belgium

\begin{tabular}{|c|c|c|c|c|c|}
\hline & Natural orpiment Kremer & $\begin{array}{l}\mathrm{g}-\mathrm{As}_{\mathbf{x}} \mathrm{S}_{\mathbf{x}} \\
\text { laboratory-made }\end{array}$ & $\begin{array}{l}\text { C90.058/ } \\
\text { P210.011 }\end{array}$ & $\begin{array}{l}\text { C90.094/ } \\
\text { P209.066 }\end{array}$ & $\begin{array}{l}\text { C90.101/ } \\
\text { P209.073 }\end{array}$ \\
\hline \multirow[t]{5}{*}{ Particle shape } & - Thin and elongated forms & \multirow{5}{*}{$\begin{array}{l}\text { Various shapes from } \\
\text { spherical to sharp-edged } \\
\text { (Figure } 4 \mathrm{C} \text { ) }\end{array}$} & \multicolumn{3}{|c|}{ - Round to elliptical-shaped particles } \\
\hline & - Laminated masses or granular and powdery & & \multirow{2}{*}{\multicolumn{3}{|c|}{$\begin{array}{l}\text { - Spherule can be smooth and round } \\
\text { - Both round and sharp edges }\end{array}$}} \\
\hline & with a fibrous structure (Figure 4a) & & & & \\
\hline & & & \multicolumn{3}{|c|}{ - Irregular sizes } \\
\hline & - No smooth and round structures & & \multicolumn{3}{|l|}{ - Figure 3} \\
\hline \multirow[t]{2}{*}{ Raman wavenumbers } & $\begin{array}{l}136,154,179,202,293,311,354 \\
367 \text { (sh), } 383 \mathrm{~cm}^{-1}\end{array}$ & $\begin{array}{l}220,235,339,367(\mathrm{sh}) \\
473 \mathrm{~cm}^{-1}\end{array}$ & \multicolumn{2}{|c|}{$\begin{array}{l}234,337,362(\mathrm{sh}) \\
471 \mathrm{~cm}^{-1}\end{array}$} & $\begin{array}{l}218,234,337,362(\mathrm{sh}), \\
471 \mathrm{~cm}^{-1}\end{array}$ \\
\hline & (Figure 6a) & (Figure 6b) & \multicolumn{2}{|c|}{ (Figure 5a, b) } & (Figure 5c) \\
\hline \multirow[t]{7}{*}{ PLM characteristics } & - Birefringent & - Strong refraction & \multicolumn{3}{|c|}{ - Isotropic and amorphous } \\
\hline & - Anisotropic & - Isotropic and amorphous & \multicolumn{3}{|c|}{ - No interference colors } \\
\hline & - Bright pink and green to blue & - No interference colors & \multicolumn{3}{|c|}{ - Full extinction } \\
\hline & interference colors & - Roundish morphology & \multirow{2}{*}{\multicolumn{3}{|c|}{$\begin{array}{l}\text { - Compressed corners and edges resulting } \\
\text { from crushing spherical particles }\end{array}$}} \\
\hline & - Foliated, micaceous structure & & & & \\
\hline & - Ductile when exposed to mechanical strain & $\begin{array}{l}\text { - Brittle, jagged } \\
\text { fracture behavior }\end{array}$ & \multicolumn{3}{|l|}{ - Figure 8} \\
\hline & - Figure 7a & - Figure 7b & & & \\
\hline
\end{tabular}


This absence strongly suggests that another material than natural orpiment was used as a starting material in the synthesis of the arsenic sulfide glass.

Different band ratios in the $\mathrm{As}_{4} \mathrm{~S}_{4}$ monomer units (as suggested by the relative intensities of the Raman bands at 234 and $362 \mathrm{~cm}^{-1}$ ) tend to show that the different $\mathrm{g}-\mathrm{As}_{\mathrm{x}} \mathrm{S}_{\mathrm{x}}$ used in the various panels were manufactured in different batches and were quenched at different temperatures. The more intense the bands for the $\mathrm{As}_{4} \mathrm{~S}_{4}$ monomer units are, the higher was the quenching temperature.

Now that the arsenic sulfide pigment found in the decorative panels of the Japanese tower has been identified as arsenic sulfide glass synthesized from arsenic trioxide and sulfur, further investigations will be conducted in order to investigate stability of the different forms of arsenic sulfide glass and the influence of media [25] and environmental factors on its degradation.

Only hypotheses can be formulated at this stage of the study. As mentioned by Grundmann and Richter [17], the artificial arsenic sulfide glass might have been introduced in order to replace the very light sensitive natural pigment. In that regard, the glassy nature of the studied pigment could be the origin of its unusual stability. Another factor determining the stability of a pigment can be its use in a lacquer-containing layer in which the pigment is embedded. The lacquer-containing binder might also protect the pigment from oxidation and light due to its high stability.

\section{Endnotes}

${ }^{\text {a }}$ The unpublished report of this study is archived at KIK-IRPA under the number 2010.10826.

bamples analyzed by py-GCMS (Thermo, Waltham, MA, USA) with TMAH $2.5 \%$ in $\mathrm{MeOH}$ and pyrolyzed at $550^{\circ} \mathrm{C}$ for $12 \mathrm{sec}$. Detailed procedure and results can be found in the unpublished report of this study archived at KIK-IRPA under the number 2010.10826.

\section{Competing interests}

The authors declare that they have no competing interests.

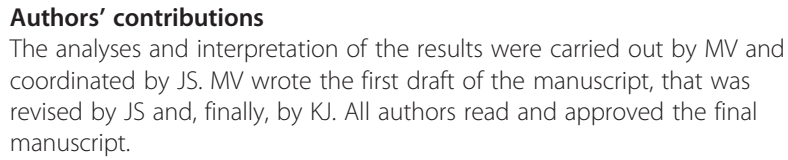
coordinated by JS. MV wrote the first draft of the manuscript, that was revised by JS and, finally, by KJ. All authors read and approved the final manuscript.

\section{Acknowledgments \\ We cordially thank Günter Grundmann for his precious advice regarding PLM and arsenic sulfide glass. This research is made possible with the support of the Belgian Science Policy Office (BELSPO) through the research program Science for a Sustainable Development - SDD, "Long-term role and fate of metal-sulfides in painted works of art - S2ART" (SD/RI/04A).}

\section{Author details}

${ }^{1}$ Laboratory of polychrome artifacts, Royal Institute for Cultural Heritage, Parc du Cinquantenaire 1, B-1000 Brussels, Belgium. ${ }^{2}$ AXES Research Group, Department of Chemistry, University of Antwerp, Groenenborgerlaan 171, 2020 Antwerp, Belgium.
Received: 7 October 2014 Accepted: 10 February 2015

Published online: 15 April 2015

\section{References}

1. Eastaugh N, Valentine W, Tracey C, Ruth S. "Realgar". The pigment compendium: optical microscopy of historical pigments. Oxford: Elsevier/ Butterworth-Heinemann; 2004. p. 128-9.

2. Rötter C. "Natürliches und künstliches Auripigment - unter Einbeziehung von Realgar". Auripigment: studien zu dem Mineral und den künstlichen Produkten = Orpiment: studies on the mineral and the artificial products. München: Siegl; 2007. p. 7-96.

3. Grundmann G, Carolin R. "Artificial orpiment": microscopic, diffractometric and chemical characteristics of synthesis products in comparison to natural orpiment, Auripigment: studien zu dem Mineral und den künstlichen Produkten = Orpiment: studies on the mineral and the artificial products. München: Siegl; 2007. p. 103-40.

4. Thirion Y. Le japonisme en France dans la seconde moitié du XIXe siècle à la faveur de la diffusion de l'estampe japonaise. Cahiersl'Assoc Int Etudes Françaises. 1961;13(1):117-30.

5. De Croës C. "La Reception Du Japonisme En Belgique”. Oriental Fascination 1889-1915, Le Japonisme En Belgique. Brussels. Belgium: Bruxelles-MuséesExposition asbl; 2008. p. 17-23.

6. Lovis B. Les natures mortes de Paul Gauguin: une production picturale méconnue. Artibus Historiae. 2009;30(59):159-79.

7. "Japonism (c.1854-1900)". Japonism (1854-1900). Web. 19 Aug. 2014. $<$ http://www.visual-arts-cork.com/history-of-art/japonism.htm>.

8. "Parc Oriental de Maulévrier". Alexandre Marcel. Web. 19 Aug. 2014. <http://www.parc-oriental.com/le-parc/histoire/alexandre-marcel/>.

9. Bournazel, Philippe. "Panorama du tour du monde". Exposition Universelle de Paris 1900. N.p., 5 May 2014. Web. 19 Aug. 2014. <http://expositionuniverselle-paris-1900.com>.

10. Verdonck A, Deceuninck M. The interior decoration of the Japanese tower at the Royal Castle Domain in Laeken". J Archit Conserv. 2012;18(2):77-99.

11. Kozyreff C. Songes d'Extrême-Asie. Antwerp, Belgium: Fonds Mercator; 2001.

12. Lewis R. "Identification and implication: orpiment on a child's coffin". Decoration surfaces on ancient Egyptian objects: Technology, Deterioration and Conservation. Cambridge, UK: Fitzwilliam Museum, University of Cambridge; 2007. p. 6-9. Lecture.

13. Fitz H, Elisabeth W. "Orpiment and Realgar". Artists' pigments: a handbook of their history and characteristics, Vol. 3. Washington: National Gallery of Art; 1997. p. 47-79.

14. Daniels V, Leach B. The Occurrence and Alteration of Realgar on Ancient Egyptian Papyri. Stud Conserv. 2004;49(2):73-84.

15. Keune K, Boon J. Can Dispersed and Migrated Arsenic from Degraded Pigments in Paintings Be a Marker for Water-Linked Transport Processes. Almada: Critério; 2011.

16. Radepont M. "Understanding of chemical reactions involved in pigment discoloration, in particular in mercury sulfide ( $\mathrm{HgS})$ blackening". Belgium: PhD thesis, University of Antwerp; 2012. p. 232.

17. Grundmann G, Mark R. "Types of dry-process artificial arsenic sulphide pigments in cultural heritage". Fatto d'archimia: los pigmentos artificiales en las técnicas pictóricas. Madrid: Ministerio de Educación, Cultura y Deporte, Subdirección General de Documentación y Publicaciones; 2012. p. 119-44.

18. Grundmann G, Natalia I, Mark R. Heike Stege, and Christoph Haisch. "The Rediscovery of Sublimed Arsenic Sulphide Pigments in Painting and Polychromy: Applications of Raman Microspectroscopy. In: Marika S,

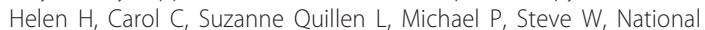
Gallery Technical Bulletin 30th Anniversary Conference National Gallery (Great Britain, editors. Studying Old Master Paintings: Technology and Practice: The National Gallery Technical Bulletin 30th Anniversary Conference Postprints. London: Archetype Publications: in association with the National Gallery; 2011. p. 269-76.

19. Eastaugh N, Valentine W, Tracey C, Ruth S. "Orpiment and arsenic sulfide, orpiment type". The pigment compendium: optical microscopy of historical pigments. Oxford: Elsevier/Butterworth-Heinemann; 2004. p. 126-7.

20. Orpiment. 2013. CAMEO (Conservation and Art Materials Encyclopedia Online). Museum of Fine Arts, Boston. Accessed February 17, 2015. http://cameo.mfa.org/wiki/Orpiment.

21. Grundmann G, Richter M. Current Research on Artificial Arsenic Sulphide Pigments in Artworks: A Short Review. CHIMIA Int J Chem. 2008;62(11):903-7. doi:10.2533/chimia.2008.903. 
22. Georgiev DG, Boolchand P, Jackson KA. Intrinsic nanoscale phase separation of bulk AsSglass. Philos Mag. 2003;83(25):2941-53.

23. Belykh AV, Kaputkina SY, Mikhailov MD, Tverjanovich AS. Photoinduced Changes of the Rate of Dissolution of Bilayer Films of Chalcogenide Glasses. Glas Phys Chem. 2012;38(2):185-9. doi:10.1134/S1087659612020022.

24. Bonazzi P, Menchetti S, Pratesi G, Muniz-Miranda M, Sbrana G. Light-Induced Variations in Realgar and Beta -As 4 S 4; X-Ray Diffraction and Raman Studies. Am Mineral. 1996;81(7-8):874-80.

25. Wallert A. Orpiment and Realgar, some pigment characteristics. Maltechnik-Restauro. 1984;90(4):45-57.

\section{Publish with ChemistryCentral and every scientist can read your work free of charge \\ "Open access provides opportunities to our colleagues in other parts of the globe, by allowing anyone to view the content free of charge." \\ W. Jeffery Hurst, The Hershey Company. \\ - available free of charge to the entire scientific community \\ - peer reviewed and published immediately upon acceptance \\ - cited in PubMed and archived on PubMed Central \\ - yours - you keep the copyright \\ Submit your manuscript here: \\ http://www.chemistrycentral.com/manuscript/<smiles>c1ccccc1</smiles> 